\title{
US health politics may give insurers a respite on genetic information
}

Washington. The need to preserve the fragile political consensus behind a health reform bill in the US Senate appears to have dissuaded one of its leading supporters from backing an amendment barring health insurance companies from using genetic information to deny coverage to potential clients.

Nancy Kassebaum (Republican, Kansas), the chair of the Senate Labor and Human Resources Committee, said last week that she was not planning to amend the Health Insurance Reform Act to include the words "genetic information" in a list of factors insurers may not use to exclude people.

This is despite the urging of scientists such as Francis Collins, the director of the National Center for Human Genome Research (NCGHR), who are concerned that uncertainty about insurance prospects is already making some individuals reluctant to participate in screening projects.

The bill, sponsored by Kassebaum and Edward Kennedy (Democrat, Massachusetts), guarantees continued insurance coverage to those who become ill or change or leave their jobs. To this end, it bars insurers from denying insurance on the basis of factors that include pre-existing medical conditions and medical history.

Although such factors do not explicitly include 'genetic information', the so-called 'report language' accompanying the bill - a plain-English synopsis intended to clarify arcane legislative language - asserts that the term 'medical history' should be read to include genetic information.

Kassebaum says that this informal language is sufficient protection. "I doubt that we would go beyond that," she said. But the informal language is not legally binding, and the concern of scientists has been expressed through Tom Harkin, (Democrat, Iowa), who tried unsuccessfully to add genetic information to the bill in committee.

Observers say Kassebaum's resistance has political roots. "The [whole] bill hangs by a very fragile majority," says Michael Tanner, a health policy analyst at the Cato Institute, a libertarian think-tank. If the bill is opened up for amendments, a "flood of proposals", both liberal and conservative, could end its prospects, he says.

Researchers are concerned that if no explicit reference is made to genetic information in the bill, individuals may be reluctant to participate in trials involving genetic testing on the grounds that this might prejudice their chances of obtaining insurance.

Indeed, some claim that this is already happening. "People certainly at least think twice about whether they want to participate," when they realize their insurance may be threatened, says Elizabeth Thomson of NCHGR, who is overseeing a multicentre trial of genetic testing and counselling for people at risk of heritable breast, ovarian and colon cancer.

But insurers insist that they must be allowed to deny coverage to individuals who may be at high risk because they carry disease susceptibility genes. Otherwise, they argue, people who are poor health risks, but who do not reveal this fact, will raise the costs of individual policies for everyone.

"We don't think it's basically fair," says Harvie Raymond, an assistant vice president at the Health Insurance Association of America, adding that it is not "appropriate" for the "viability and profitability" of insurance companies. He adds that fears about insurers using genetic information to exclude people are unwarranted, given the existing restrictions in the KassebaumKennedy bill.

But Collins, who co-chaired a working group last year whose report proposed both state and federal legislators should move to prevent genetic discrimination in health insurance, disagrees. He urged Kassebaum, at a hearing of the Senate committee last week, to include the words 'genetic information' explicitly in the bill. "If you limit this category to medical history, you're going to miss some people," he said.

Collins argued, for example, that under the bill as drafted, insurers might be able to deny coverage to individuals who were shown by genetic tests to carry genes for recessive disorders such as cystic fibrosis.

Also affected, said Collins, could be women such as those in a recent study of $B R C A-1$ mutations associated with earlyonset breast cancer. Nearly half of such women with mutations had no family history of the disease, as the mutation had been carried asymptomatically by their fathers, Collins said.

The Kassebaum-Kennedy bill is expected to reach the Senate floor in the third week of April. As written, it has strong backing, with 51 out of 100 senators agreeing to act as co-sponsors. A Republican initiative in the House of Representatives which is intended to match the Senate bill contains no reference to genetic information. It is expected to reach the House floor in the last week of March. Meredith Wadman See also report on page 96.

\section{Hubble brings Pluto's surface into view}

\begin{abstract}
Washington. The first detailed images of the surface of the planet Pluto, taken by the Hubble Space Telescope in 1994 and unveiled at $a$ press conference last week, show a world with more large-scale contrast than any planet in the Solar System except Earth.
\end{abstract}

Up to a dozen

distinct albedo features - dark and light provinces - appear in the pictures (above right), which are still being analysed by Alan Stern of the Southwest Research Institute in Boulder, Colorado, Marc Buie of the Lowell Observatory in Flagstaff, Arizona, and Laurence Trafton of the University of Texas at Austin.

The large images shown here are reprojections based on surface maps
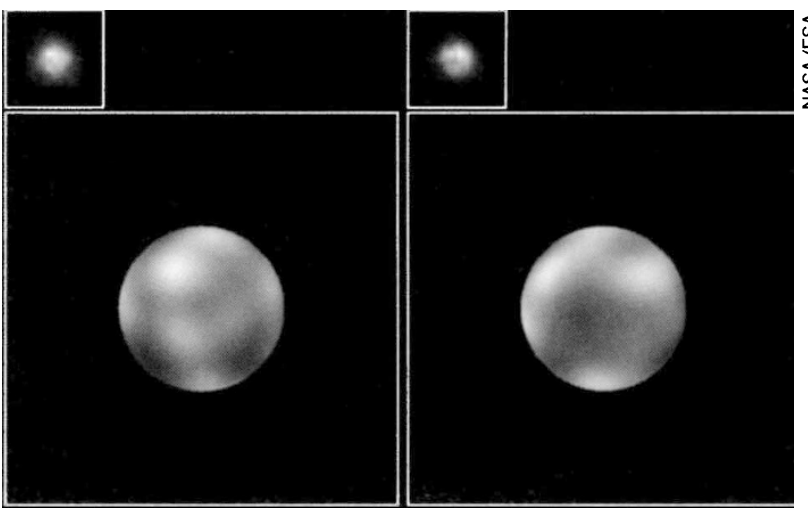

created from the original Hubble images, which are shown as insets.

The images, using photographs taken with the European Space Agency's Faint Object Camera, show bright polar caps (believed to be areas of nitrogen frost), a bright equatorial spot that rotates with the planet, and several 'dark' regions (probably where sunlight has broken down surface hydrocarbons).
Tony Reichhardt 